\title{
Association between breast feeding and growth: the Boyd-Orr cohort study
}

\author{
R M Martin, G Davey Smith, P Mangtani, S Frankel, D Gunnell
}

Arch Dis Child Fetal Neonatal Ed 2002;87:F193-F201

See end of article for authors' affiliations

Correspondence to

Dr Martin, Department of

Social Medicine, University

of Bristol, Canynge Hall,

Whiteladies Road, Bristol

BS8 2PR, UK;

richard.martin@bristol.ac.uk

Accepted 30 April 2002

\begin{abstract}
Objective: To investigate the association of breast feeding with height and body mass index in childhood and adulthood.

Design: Historical cohort study, based on long term follow up of the Carnegie (Boyd-Orr) survey of diet and health in pre-war Britain (1937-1939).

Setting: Sixteen urban and rural districts in Britain.

Subjects: A total of 4999 children from 1352 families were surveyed in 1937-1939. Information on infant feeding and childhood anthropometry was available for 2995 subjects.

Main outcome measures: Mean differences in childhood and adult anthropometry between breast and bottle fed subjects.

Results: Breast feeding was associated with the survey district, greater household income, and food expenditure, but not with number of children in the household, birth order, or social class. In childhood, breast fed subjects were significantly taller than bottle fed subjects after controlling for socioeconomic variables. The mean height difference among boys was 0.20 standard deviation (SD) $195 \%$ confidence interval (Cl) 0.07 to 0.32$)$, and among girls it was $0.14 \mathrm{SD}(95 \% \mathrm{Cl} 0.02$ to 0.27$)$. Leg length, but not trunk length, was the component of height associated with breast feeding. In males, breast feeding was associated with greater adult height (difference: $0.34 \mathrm{SD}, 95 \% \mathrm{Cl} 0.13$ to 0.55 ); of the two components of height, leg length $(0.26 \mathrm{SD}, 95 \% \mathrm{Cl} 0.02$ to 0.50$)$ was more strongly related to breast feeding than trunk length $(0.16 \mathrm{SD}, 95 \% \mathrm{Cl}-0.04$ to 0.35$)$. Height and leg length differences were in the same direction but smaller among adult females. There was no association between breast feeding and body mass index in childhood or adulthood.

Conclusions: Compared with bottle fed infants, infants breast fed in the 1920s and 1930s were taller in childhood and adulthood. As stature is associated with health and life expectancy, the possible long term impact of infant feeding on adult mortality patterns merits further investigation.
\end{abstract}

$\mathrm{T}$ he benefits of breast feeding during infancy are well known, but the effects on childhood and adult health are less clear. ${ }^{1}$ Cohort studies suggest that breast feeding is associated with reduced adult serum cholesterol concentrations, ${ }^{23}$ ischaemic heart disease mortality, ${ }^{4}$ noninsulin dependent diabetes mellitus, ${ }^{5}$ and Helicobacter pylori infection, ${ }^{6}$ although protective effects have not been found in all studies, ${ }^{7}$ and in some animal models breast feeding is associated with atherogenic cholesterol profiles. ${ }^{8}$ However, these studies are difficult to interpret for several reasons. Firstly, those who are breast fed may be different from those who are bottle fed, for example with respect to socioeconomic confounding factors related to future health. ${ }^{9}$ The potential for socioeconomic confounding, and its direction, may be different at different time periods because socioeconomic patterns of breast feeding have varied throughout the 20th century. ${ }^{10}{ }^{11}$ Secondly, previous studies of breast feeding and later health have generally adjusted only for one marker of socioeconomic conditions, usually adulthood social class, which may not accurately reflect the underlying confounding exposures of interest.

As well as reflecting genetic factors, height is an accepted marker for childhood diet and health throughout the growing years. ${ }^{12}$ Childhood and adult stature is in turn related to future cause specific morbidity and mortality, providing evidence for an influence of early life factors on later health. ${ }^{13-15}$ Leg length appears to be the component of childhood height most sensitive to early adverse dietary and economic exposures. ${ }^{16-19}$ Leg length is also the component of height most strongly related to cause specific mortality. ${ }^{13}$ However, the specific dietary and environmental exposures associated with height earlier this century are only starting to be elucidated. ${ }^{16}$ In a recent study, increased duration of breast feeding was associated with reduced prevalence of childhood overweight and obesity. ${ }^{20}$ However, this association may reflect incomplete adjustment for social factors associated with breast feeding today, ${ }^{21}$ which are currently more pronounced than they were earlier this century. ${ }^{22}$

The Carnegie (Boyd-Orr) survey of diet and health in pre-war Britain was a large cross sectional survey involving 1352 families. As part of this survey, data on breast feeding incidence and duration and a variety of socioeconomic and anthropometric variables were collected. ${ }^{23}{ }^{24}$ The aim of this analysis was to investigate the association between breast feeding in the 1930s and (a) a wide range of family level socioeconomic variables, and $(b)$ childhood and adult height, the components of height (leg length and trunk length), and body mass index (BMI).

\section{MATERIALS AND METHODS The Carnegie survey}

The Carnegie survey was a cross sectional study of diet, social circumstances, and health carried out in 16 urban and rural districts in Britain between 1937 and 1939. The sampling frame and examination methods used have been described in detail elsewhere. ${ }^{23}{ }^{24}$ Briefly, 1352 families were surveyed, and the cohort is based on the records of 4999 children from these families who were aged between zero and 19 years at the time of the survey. ${ }^{23}$ The number of subjects has increased slightly since earlier publications as a result of further searches of archived records and contacts with surviving study members. 
Families were generally identified from the more deprived localities through contacts made by local health workers, and two thirds consented to participation. ${ }^{24}$ The survey records have been retrieved from archives at the Rowett Research Institute, Aberdeen, and individuals have been traced using the National Health Service Central Register. Cross sectional data on childhood anthropometry and infant feeding methods were recorded for 2995 subjects (60\%) from 1072 families. The reduced number available for analysis is mainly because in two centres medical examinations were not performed.

\section{Infant feeding}

Details of the method of infant feeding and duration of breast feeding were obtained from the mother at the time of the survey for each child aged 0-19 years. Thus breast feeding occurred between 1918 and 1939, depending on the age of the child at measurement. We coded subjects as breast fed (at least two weeks) or bottle fed; for breast fed infants, we coded breast feeding duration as: two weeks to $<$ two months; $\geqslant$ two to $<$ six months; $\geqslant$ six to $<12$ months; $\geqslant 12$ months; and unknown. The six month cut off reflects the contemporaneously recommended weaning age..$^{25}$ The $\geqslant 12$ month category reflects prolonged breast feeding.

\section{Sociodemographic variables}

Per capita weekly household expenditure on food, income, and household size were obtained from the original survey material. ${ }^{23}$ Birth order was based on the child's position among the children living in the household at the time of the survey, and social class of the head of the household was assigned using the Registrar General's 1931 classification. ${ }^{24}$

\section{Childhood anthropometry}

The techniques used to measure standing height, leg length, and body weight have previously been described. ${ }^{23}$ Standing height was measured to the nearest millimetre with a portable measuring stand. Leg length was measured with a steel tape measure and recorded as the distance from the ground to the summit of the iliac crest. Trunk length was calculated by subtracting leg length from overall height. Using these data internally, age and sex standardised z scores for height, leg length, trunk length, and BMI were computed using polynomial regression techniques. ${ }^{13}{ }^{16}$ The $\mathrm{z}$ scores for BMI were based on the reciprocal transformation of BMI. ${ }^{26}$

As height measurement in children under 2 years of age tends to be unreliable and because of a large number of missing data in children of this age and in the 15 and over age band, $\mathrm{z}$ scores were calculated only for children aged between 2 and 14 years 9 months as in previous reports ${ }^{13}$ - that is, children breast fed between 1922 and 1937. Internally derived standards have been used because no acceptable cross sectional reference standards exist for childrens' heights and weights in the 1930s. ${ }^{13}$ For children 8 years of age and under, each unit of $\mathrm{z}$ score for childhood height and leg length is approximately equivalent to $4-6 \mathrm{~cm}$ and $3-4 \mathrm{~cm}$ respectively, and for children over 8 years of age each unit of $\mathrm{z}$ score for childhood height and leg length is approximately equivalent to 6-9 $\mathrm{cm}$ and $4-6 \mathrm{~cm}$ respectively. Of those aged between 2 years and 14 years 9 months, information on both breast feeding status and height, trunk length, leg length, and BMI was available on 2455, 2366, 2369, and 2444 subjects respectively.

For 416 of the subjects with breast feeding data, there were data on measured birth weight in pounds and ounces. ${ }^{27}$ These data were used to assess whether birth weight was associated with breast feeding in this subsample.

\section{Follow up self reported anthropometry}

Between 1997 and 1998, all 3182 surviving members of the Boyd-Orr cohort traced at the National Health Service Central
Register were sent health and lifestyle questionnaires. ${ }^{28}$ As part of the survey, subjects were asked to report their current height (in feet and inches), inside leg measurement (in inches), and weight in light clothing (in stones and pounds). After two reminders, 1647 completed questionnaires were returned (52\% response). From these, information on adult height, trunk length, leg length, and BMI was available for $1029,746,761$, and 999 respectively of the subjects with childhood breast feeding data. In a validation study on a subsample (294) of these subjects, correlations between self report and measured height and weight were over 0.90 and for leg length were over $0.70 .^{28}$ Shorter people and older people tended to over-report their height, and the overweight underreported their weight. ${ }^{28}$

Surviving members of the Boyd-Orr cohort were also asked about parental height. Data were available on maternal and paternal heights for 787 offspring with breast feeding data. The mean maternal and paternal heights reported by individuals in each family were used to assess whether breast feeding was associated with maternal or paternal height in this subsample.

\section{Statistical analysis}

All analyses were performed using Stata release 7.0. ${ }^{29}$ The age, sex, and geographical (survey district) distributions of breast feeding status and breast feeding duration were compared using unpaired $t$ tests, the Wilcoxon rank sum test, and the $\chi^{2}$ test for heterogeneity as appropriate. Mean birth weights and parental heights in never and ever breast fed children were compared using unpaired $t$ tests.

Associations between breast feeding and socioeconomic factors were investigated using logistic regression. Clustering effects may have arisen because several cohort members belonged to the same families and therefore shared genetic influences on anthropometry, as well as childhood socioeconomic conditions and propensity to being breast fed. To account for this, we estimated robust standard errors ${ }^{30}$ adjusted for clustering at the family level for the association between breast feeding and socioeconomic variables. Separate models with additional adjustment for age and survey district were also fitted. Associations between breast feeding and anthropometry (age and sex standardised z scores for height, leg length, trunk length, and BMI) were examined by random effects linear regression modelling using the maximum likelihood estimator. This allowed for between-family differences in mean height. Separate models with additional adjustment for socioeconomic factors (social class, number of children, birth order, and income category, all entered as categorical variables) and survey district were also fitted. All effect estimates were calculated on the same subset of subjects with complete data for the index dependent variable and all covariates adjusted for, in order to ensure an unbiased assessment of confounding.

Likelihood ratio tests were used to assess whether the association of breast feeding with anthropometry differed with respect to age, sex, and income group (interaction). To assess effect modification by age on childhood anthropometry, we investigated associations between breast feeding and anthropometry in two age bands: children aged 8 years or less and those aged over 8 years. Eight years of age was chosen so that there were approximately equal numbers of survey members in each group and to ensure that all children in the younger age group were prepubertal.

To further investigate the potential for confounding by shared environmental exposures other than breast feeding, the association between breast feeding and stature was also estimated in the subset of families who had at least one pair of children discordant for breast feeding status. 
Table 1 Association between breast feeding and socioeconomic variables, Boyd-Orr cohort, UK

\begin{tabular}{|c|c|c|c|c|c|c|c|}
\hline \multirow[b]{2}{*}{ Variable } & \multirow{2}{*}{$\begin{array}{l}\text { No in subset } \\
\text { with complete } \\
\text { data for } \\
\text { adjusted } \\
\text { analyses* }\end{array}$} & \multicolumn{4}{|c|}{ Infant feeding status } & \multicolumn{2}{|l|}{ Odds ratio $(95 \% \mathrm{Cl})$} \\
\hline & & \multicolumn{2}{|c|}{ Breast fed } & \multicolumn{2}{|c|}{ Bottle fed } & Adjusted for age $\dagger$ & $\begin{array}{l}\text { Adjusted for aget } \\
\text { and survey district }\end{array}$ \\
\hline Mean (SD) no of children $\ddagger$ & 2987 & \multicolumn{2}{|c|}{$4.6(2.0)$} & \multicolumn{2}{|c|}{$4.6(2.2)$} & $\begin{array}{l}0.99(0.92 \text { to } 1.06) \\
p=0.72\end{array}$ & $\begin{array}{l}0.96(0.89 \text { to } 1.03) \\
p=0.23\end{array}$ \\
\hline Birth order (\%) & 2994 & & & & & & \\
\hline 1 & & 479 & $(70.8)$ & 198 & (29.3) & 1.00 & 1.00 \\
\hline 2 & & 517 & (73.5) & 186 & (26.5) & 1.15 (0.94 to 1.40$)$ & $1.16(0.95$ to 1.43$)$ \\
\hline 3 & & 445 & (74.4) & 153 & $(25.6)$ & $1.20(0.94$ to 1.53$)$ & $1.18(0.92$ to 1.52$)$ \\
\hline $4+$ & & 736 & (72.4) & 280 & $(27.6)$ & $1.08(0.79$ to 1.48$)$ & 1.01 (0.73 to 1.39 ) \\
\hline Trend & & & & & & $\begin{array}{l}1.02(0.92 \text { to } 1.13) ; \\
p=0.69\end{array}$ & $\begin{array}{l}1.00(0.89 \text { to } 1.11) \\
p=0.95\end{array}$ \\
\hline Income group (\%)§ & 2968 & & & & & & \\
\hline$<10$ s & & 1547 & (72.3) & 593 & (27.7) & 1.00 & 1.00 \\
\hline $10-15 s$ & & 392 & (73.1) & 144 & (26.9) & 1.05 (0.78 to 1.39$)$ & $1.12(0.83$ to 1.52$)$ \\
\hline$>15-20 \mathrm{~s}$ & & 101 & (72.1) & 39 & (27.9) & $0.99(0.60$ to 1.66$)$ & $1.13(0.67$ to 1.89 ) \\
\hline$>20 s$ & & 123 & $(80.4)$ & 30 & (19.6) & 1.59 (0.96 to 2.63$)$ & 1.79 (1.04 to 3.08$)$ \\
\hline Trend per category of income & & & & & & $\begin{array}{l}1.10(0.96 \text { to } 1.26) ; \\
p=0.18\end{array}$ & $\begin{array}{l}1.16(1.00 \text { to } 1.34) ; \\
p=0.05\end{array}$ \\
\hline Expenditure group (\%) \|| & 2987 & & & & & & \\
\hline$\leqslant 4 \mathrm{~s} 11.75 \mathrm{~d}$ & & 1226 & (72.3) & 471 & $(27.8)$ & 1.00 & 1.00 \\
\hline $5 s-6 s 11.75 d$ & & 564 & (73.2) & 207 & (26.9) & $1.05(0.78$ to 1.40$)$ & $1.29(0.93$ to 1.78$)$ \\
\hline $7 s-8 s 11.75 d$ & & 227 & (72.1) & 88 & (27.9) & 0.99 (0.68 to 1.44$)$ & $1.20(0.82$ to 1.76$)$ \\
\hline$>9 s$ & & 154 & (75.1) & 51 & (24.9) & $1.17(0.77$ to 1.78$)$ & $1.50(0.96$ to 2.34$)$ \\
\hline Trend per category of expenditure & & & & & & $\begin{array}{l}1.03(0.91 \text { to } 1.17) ; \\
p=0.61\end{array}$ & $\begin{array}{l}1.14(0.99 \text { to } 1.31) ; \\
p=0.07\end{array}$ \\
\hline Social class (\%)ף & 2744 & & & & & & \\
\hline I/II & & 128 & (72.7) & 48 & (27.3) & 1.00 & 1.00 \\
\hline III & & 392 & (69.1) & 175 & (30.9) & 0.84 (0.47 to 1.49 ) & $0.71(0.39$ to 1.28$)$ \\
\hline IV & & 433 & (71.7) & 171 & (28.3) & 0.95 (0.54 to 1.65$)$ & $1.02(0.57$ to 1.81$)$ \\
\hline V & & 346 & (72.4) & 132 & $(27.6)$ & $0.98(0.53$ to 1.80$)$ & $0.76(0.41$ to 1.41$)$ \\
\hline Unemployed & & 695 & (75.6) & 224 & (24.4) & $1.16(0.66$ to 2.04$)$ & $0.82(0.45$ to 1.49$)$ \\
\hline Trend per category of social class & & & & & & $\begin{array}{l}1.08(0.98 \text { to } 1.19) ; \\
p=0.13\end{array}$ & $\begin{array}{l}1.00(0.89 \text { to } 1.12) ; \\
p=0.98\end{array}$ \\
\hline
\end{tabular}

Odds ratios calculated using logistic regression with standard errors adjusted for clustering at the family level.

* Odds ratios were calculated on the same subset of subjects with full data for the index explanatory variable and all covariates adjusted for, in order to ensure an unbiased assessment of confounding.

$\dagger$ Age entered as a continuous variable.

$\ddagger$ Number of children entered as a continuous variable.

$\S$ Income (shillings; s) per head per week as recorded in original survey, but with the original last three groups collapsed into a single category.

$\|$ Shillings and pence per head per week spent on food as recorded in the original survey but with the original last three groups collapsed into a single category.

IAssigned using the Registrar General's 1931 classification of occupations from social class I (professional) to social class $\vee$ (unskilled manual).

\section{RESULTS}

\section{Factors associated with breast feeding}

A total of $2178(72.7 \%)$ subjects were breast fed for at least two weeks $(4.3 \%$ of subjects were breast fed but for less than two weeks). There were no differences in the proportion of males $(72.8 \%)$ and females $(72.6 \%)$ who were breast fed. The median duration of breast feeding was nine months and was the same in males and females $(p=0.46)$. The mean (SD) ages of breast fed (6.8 (4.0) years) and bottle fed (6.9 (4.0) years) children were similar at the time they were measured in childhood. Breast feeding rates differed substantially in different survey locations, varying from $59.0 \%$ to $85.7 \%$ ( $p<0.0001$ ).

Breast feeding was not associated with the number of children in the household, the child's birth order, or the social class of the head of the household (table 1). Families with a weekly per capita income of over 20 shillings were more likely to breast feed $(80.4 \%)$ than families with an income of less than 10 shillings $(72.3 \%)$. The adjusted odds ratio (OR) comparing the highest with the lowest income groups was 1.79 (95\% confidence interval (CI) 1.04 to 3.08). There was evidence that expenditure on food was associated with breast feeding after adjustment for survey district (OR for trend: 1.14 (95\% CI 0.99 to 1.31$)$ ), but this was of borderline significance. For the children with birthweight data $(n=416)$, there was no difference in the mean birth weights of breast fed ( $7 \mathrm{lbs} 8.3$ oz) and bottle fed (7 lbs $9.7 \mathrm{oz}$ ) children (difference $1.4 \mathrm{oz}$ (95\% CI -3.3 to 6.1 ); $p=0.56$ ). For those with data on parental height $(\mathrm{n}=787)$, there were no differences between breast and bottle fed children in mean maternal $(161.2 v 160.5 \mathrm{~cm}$; $\mathrm{p}=0.24)$ and paternal $(172.1 \vee 172.3 \mathrm{~cm} ; \mathrm{p}=0.75)$ heights.

When duration of breast feeding was examined in relation to socioeconomic factors (table 2 ), there was a suggestion that although children from affluent families were more likely to be breast fed, breast feeding was continued for shorter time periods.

\section{Breast feeding and childhood growth}

Table 3 shows the sex specific mean differences between breast and bottle fed subjects in relation to childhood stature and BMI. There was no association between breast feeding and BMI in childhood. However, breast fed subjects were significantly taller than bottle fed subjects; in fully adjusted models, breast fed boys were on average 0.20 SD (95\% CI 0.07 to 0.32 ) taller than bottle fed boys; breast fed girls were on average 0.14 SD (95\% CI 0.02 to 0.27 ) taller than bottle fed girls. When trunk length and leg length were examined separately, leg length was the component of childhood height most strongly related to breast feeding. The association between breast feeding and leg length appeared to be stronger in boys (0.23 SD; $95 \%$ CI 0.10 to 0.36 ) than girls ( 0.13 SD; $95 \%$ CI 0.01 
Table 2 Association between duration of breast feeding* and selected socioeconomic variables, Boyd-Orr cohort, UK

\begin{tabular}{|c|c|c|c|c|}
\hline & $\begin{array}{l}2 \text { weeks to }<2 \\
\text { months }\end{array}$ & $\geqslant 2$ to 6 months & $\begin{array}{l}\geqslant 6 \text { to } 12 \\
s \text { months }\end{array}$ & $\begin{array}{l}\text { Over } 12 \\
\text { months }\end{array}$ \\
\hline \multicolumn{5}{|l|}{ Income group $(\%) \dagger$} \\
\hline$>20 \mathrm{~s}$ & $16(14.7)$ & $27(24.8)$ & $60(55.1)$ & $6(5.5)$ \\
\hline$>15-20 s$ & $9(10.3)$ & $22(25.3)$ & 49 (56.3) & 7 (8.1) \\
\hline $10-15 s$ & $15(4.5)$ & $105(31.3)$ & $178(53.0)$ & 38 (11.3) \\
\hline$<10$ s & $85(6.5)$ & $302(23.2)$ & 745 (57.3) & $168(12.9)$ \\
\hline \multicolumn{4}{|l|}{$\chi^{2}$ test for heterogeneity (9 df) } & $p=0.001$ \\
\hline \multicolumn{5}{|l|}{ Expenditure group $(\%) \ddagger$} \\
\hline$>9 \mathrm{~s}$ & $18(13.2)$ & $34(25.0)$ & $75(55.2)$ & $9(6.6)$ \\
\hline $7 s-8 s 11.75 d$ & $9(4.8)$ & $52(27.8)$ & 105 (56.2) & $21(11.2)$ \\
\hline $5 s-6 s 11.75 d$ & $46(9.4)$ & $138(28.2)$ & $245(50.0)$ & $61(12.5)$ \\
\hline$\leqslant 4 \mathrm{~s} 11.75 \mathrm{~d}$ & $52(5.1)$ & $237(23.1)$ & $608(59.2)$ & $130(12.7)$ \\
\hline \multicolumn{4}{|l|}{$\chi^{2}$ test for heterogeneity (9 df) } & $p<0.0001$ \\
\hline \multicolumn{5}{|l|}{ Social class $(\%) \S$} \\
\hline I/II & $12(10.3)$ & $37(31.9)$ & $61(52.6)$ & $6(5.2)$ \\
\hline III & $18(5.4)$ & $115(34.2)$ & $182(54.2)$ & $21(6.3)$ \\
\hline IV & $32(8.2)$ & $93(23.9)$ & $207(53.1)$ & $58(14.9)$ \\
\hline V & $16(5.8)$ & $65(23.6)$ & $160(58.2)$ & $34(12.4)$ \\
\hline Unemployed & $46(8.0)$ & $116(20.1)$ & $336(58.2)$ & 79 (13.7) \\
\hline$\chi^{2}$ test for heterogeneity (12 df) & & & & $p<0.0001$ \\
\hline \multicolumn{5}{|c|}{$\begin{array}{l}\text { Percentages (in parentheses) relate to row totals. } \\
\text { *Excluding duration unknown. } \\
\text { †Income (shillings; s) per head per week as recorded in original survey, but with the original last three } \\
\text { groups collapsed into a single category. } \\
\text { †Shillings and pence per head per week spent on food as recorded in original survey but with the original } \\
\text { last three groups collapsed into a single category. } \\
\S \text { Assigned using the Registrar General's } 1931 \text { classification of occupations from social class I (professional) } \\
\text { to social class V (unskilled manual). }\end{array}$} \\
\hline
\end{tabular}

to 0.26$)$. However, there was no statistical evidence of interaction between sex and breast feeding on childhood leg length $(p=0.28)$, height $(p=0.83)$, trunk length $(0.48)$, or BMI $(p=0.11)$. There was also no statistical evidence of interaction between family income and breast feeding on any of the growth variables. The associations between breast feeding and childhood height and leg length were also observed when the analysis was restricted to families in whom there were children with discordant breast feeding history (height: $\mathrm{n}=191$ families and 615 individuals; mean height difference (boys and girls), breast $v$ bottle fed: 0.10 SD (95\% CI -0.01 to $0.21 ; \mathrm{p}=0.075)$; leg length: $\mathrm{n}=180$ families and 562 individuals; mean leg length difference: 0.15 SD (95\% CI 0.03 to $0.26 ; \mathrm{p}=0.012)$ ). There was no association between breast feeding and trunk length in families in whom there were children with discordant breast feeding history (mean trunk length difference: -0.05 SD (95\% CI -0.18 to $0.08 ; \mathrm{p}=0.45)$ ). The median duration of breast feeding among those siblings who were breast fed in this subsample was nine months (equivalent to the whole sample).

There was evidence of interaction between age and breast feeding on height $(p=0.014)$, leg length $(p=0.006)$, and trunk length $(p=0.069)$, but not on BMI $(p=0.18)$. Table 4 presents breast feeding/growth associations in children aged 8 years or less and in those aged over 8 years (the pre-specified age categories). As there was no evidence of interaction between sex and breast feeding on growth, results are presented for boys and girls combined. The positive association of breast feeding with height was greater in those aged over 8 than in those under 8 . Therefore, age specific associations of breast feeding with anthropometry were investigated in more detail using two year age bands (fig 1). There was some evidence of a linear increase in the effect of breast feeding on height ( $p$ for trend: 0.034$)$ and leg length ( $p$ for trend: 0.006), but not trunk length ( $p$ for trend: 0.14) with increasing age group.

Figure 2 shows the association between duration of breast feeding and childhood anthropometry. There was no evidence of an increase in BMI for each unit increase in duration of breast feeding category compared with bottle feeding as the baseline group $(0.02 \mathrm{SD} ; 95 \% \mathrm{CI}-0.01$ to $0.05 ; \mathrm{p}=0.23)$. Although there was statistical evidence of an increase in height (0.06 SD; 95\% CI 0.03 to $0.09 ; \mathrm{p}<0.0001)$ and leg length (0.06 SD; 95\% CI 0.03 to 0.09; $p<0.0001)$ for each unit increase in duration of breast feeding category, there was no clear evidence of a dose response after two months.

\section{Breast feeding and adult size}

Table 5 shows the associations between breast feeding and self reported adult anthropometry. There was no relation between breast feeding and adult BMI, but among males the associations of breast feeding with adult height and leg length seen in children persisted into adulthood in the fully adjusted models (mean height difference: $2.49 \mathrm{~cm}$ (95\% CI 0.94 to 4.03); mean leg length difference: $1.25 \mathrm{~cm}$ (95\% CI 0.09 to $2.40)$ ). Expressed in terms of $\mathrm{z}$ scores, the fully adjusted mean height and leg length differences were 0.34 SD (95\% CI 0.13 to $0.55 ; \mathrm{p}=0.002)$ and 0.26 SD $(95 \%$ CI 0.02 to $0.50 ; p=0.034)$ respectively. There were also positive associations of breast feeding with height and leg length among adult females, but these were smaller than those observed in adult males and of borderline significance. There was no association between breast feeding and adult height when the analysis was restricted to families in whom there were children with discordant breast feeding history $(\mathrm{n}=70$ families and 178 individuals; mean height difference: $-0.81 \mathrm{~cm}$ (95\% CI -3.55 to $1.93 ; \mathrm{p}=0.56$ ), although the sample available for this analysis was small.

\section{DISCUSSION \\ Main findings}

As far as we are aware, this is the first study to investigate the long term influences of breast feeding on both height and weight beyond mid childhood and into adulthood. We found that, in children examined in the late 1930s in the Carnegie (Boyd Orr) survey, breast feeding in the 1920s and 1930s was 
Table 3 Association between breast feeding and childhood anthropometric variables, Boyd-Orr cohort, UK

\begin{tabular}{|c|c|c|c|c|c|}
\hline \multirow[b]{2}{*}{ Variable* } & \multirow[b]{2}{*}{$\begin{array}{l}\text { No in subset with } \\
\text { complete data }\end{array}$} & \multicolumn{2}{|c|}{ Mean (SD) anthropometric z score } & \multicolumn{2}{|c|}{$\begin{array}{l}\text { Mean difference }(95 \% \mathrm{Cl}) \text { in z scores (breast fed minus } \\
\text { bottle fed) }\end{array}$} \\
\hline & & Breast fed & Bottle fed & $\begin{array}{l}\text { Adjusted for clustering } \\
\text { at the family level }\end{array}$ & $\begin{array}{l}\text { Also adjusted for } \\
\text { socioeconomic factorst } \\
\text { and survey district }\end{array}$ \\
\hline \multicolumn{6}{|l|}{ Males } \\
\hline Height & 1059 & $0.054(0.97)$ & $-0.168(0.99)$ & $\begin{array}{l}0.19(0.06 \text { to } 0.33) \\
p=0.005\end{array}$ & $\begin{array}{l}0.20(0.07 \text { to } 0.32) \\
p=0.003\end{array}$ \\
\hline Trunk length & 1023 & $0.083(0.98)$ & $-0.102(1.00)$ & $\begin{array}{l}0.12(-0.02 \text { to } 0.26) \\
p=0.11\end{array}$ & $\begin{array}{l}0.04(-0.10 \text { to } 0.17) \\
p=0.59\end{array}$ \\
\hline Leg length & 1023 & $0.015(0.97)$ & $-0.158(0.99)$ & $\begin{array}{l}0.18(0.04 \text { to } 0.31) \\
p=0.01\end{array}$ & $\begin{array}{l}0.23(0.10 \text { to } 0.36) \\
p<0.0001\end{array}$ \\
\hline Body mass index & 1055 & $0.004(0.97)$ & $0.001(1.09)$ & $\begin{array}{l}0.001(-0.14 \text { to } 0.14) \\
p=0.95\end{array}$ & $\begin{array}{l}-0.03(-0.17 \text { to } 0.11) \\
p=0.72\end{array}$ \\
\hline \multicolumn{6}{|l|}{ Females } \\
\hline Height & 1156 & $0.039(0.97)$ & $-0.094(1.00)$ & $\begin{array}{l}0.12(-0.01 \text { to } 0.24) \\
p=0.08\end{array}$ & $\begin{array}{l}0.14(0.02 \text { to } 0.27) \\
p=0.02\end{array}$ \\
\hline Trunk length & 1112 & $0.084(0.98)$ & $-0.052(1.00)$ & $\begin{array}{l}0.12(-0.01 \text { to } 0.26) \\
p=0.07\end{array}$ & $\begin{array}{l}0.11(-0.02 \text { to } 0.23) \\
p=0.10\end{array}$ \\
\hline Leg length & 1114 & $-0.004(0.97)$ & $-0.082(1.01)$ & $\begin{array}{l}0.08(-0.05 \text { to } 0.21) \\
p=0.21\end{array}$ & $\begin{array}{l}0.13(0.01 \text { to } 0.26) \\
p=0.04\end{array}$ \\
\hline Body mass index & 1150 & $0.030(0.99)$ & $-0.084(1.00)$ & $\begin{array}{l}0.09(-0.04 \text { to } 0.22) \\
p=0.18\end{array}$ & $\begin{array}{l}0.08(-0.05 \text { to } 0.21) \\
p=0.25\end{array}$ \\
\hline
\end{tabular}

Mean differences between breast fed and bottle fed subjects were calculated using random effects regression modelling.

*Internally age and sex standardised $z$ scores calculated for children aged 2 years to 14 years 9 months.

†Socioeconomic factors adjusted for were social class, number of children, birth order, and income category (all entered as categorical variables).

Table 4 Age specific association between breast feeding and childhood anthropometric variables, Boyd-Orr cohort, UK

\begin{tabular}{|c|c|c|c|c|c|}
\hline \multirow[b]{2}{*}{ Variable* } & \multirow[b]{2}{*}{$\begin{array}{l}\text { No in subset with } \\
\text { complete data }\end{array}$} & \multicolumn{2}{|c|}{ Mean (SD) anthropometric z score } & \multicolumn{2}{|c|}{$\begin{array}{l}\text { Mean difference }(95 \% \mathrm{Cl}) \text { in z scores (breast fed minus } \\
\text { bottle fed) }\end{array}$} \\
\hline & & Breast fed & Bottle fed & $\begin{array}{l}\text { Adjusted for clustering } \\
\text { at the family level }\end{array}$ & $\begin{array}{l}\text { Also adjusted for } \\
\text { socioeconomic factorst } \\
\text { and survey district }\end{array}$ \\
\hline \multicolumn{6}{|l|}{ Age 8 years or less } \\
\hline Height & 1178 & $-0.006(0.96)$ & $-0.07(1.01)$ & $\begin{array}{l}0.10(-0.03 \text { to } 0.22) \\
p=0.13\end{array}$ & $\begin{array}{l}0.12(-0.01 \text { to } 0.24) \\
p=0.06\end{array}$ \\
\hline Trunk length & 1109 & $0.03 \quad(0.99)$ & $-0.06(1.00)$ & $\begin{array}{l}0.06(-0.07 \text { to } 0.20) \\
p=0.37\end{array}$ & $\begin{array}{l}-0.001(-0.13 \text { to } 0.13) \\
p=0.99\end{array}$ \\
\hline Leg length & 1111 & $-0.04 \quad(0.94)$ & $-0.03(1.04)$ & $\begin{array}{l}0.04(-0.09 \text { to } 0.17) \\
p=0.53\end{array}$ & $\begin{array}{l}0.11(-0.01 \text { to } 0.23) \\
p=0.08\end{array}$ \\
\hline Body mass index & 1172 & $0.002(0.97)$ & $-0.09(1.06)$ & $\begin{array}{l}0.07(-0.06 \text { to } 0.20) \\
p=0.30\end{array}$ & $\begin{array}{l}0.03(-0.11 \text { to } 0.16) \\
p=0.69\end{array}$ \\
\hline \multicolumn{6}{|l|}{ Age over 8 years } \\
\hline Height & 1037 & $0.11 \quad(0.98)$ & $-0.19(0.98)$ & $\begin{array}{l}0.25(0.11 \text { to } 0.38) \\
p<0.001\end{array}$ & $\begin{array}{l}0.25(0.12 \text { to } 0.38) \\
p<0.001\end{array}$ \\
\hline Trunk length & 1026 & $0.14 \quad(0.97)$ & $-0.09(0.99)$ & $\begin{array}{l}0.17(0.03 \text { to } 0.31) \\
p=0.019\end{array}$ & $\begin{array}{l}0.14(0.01 \text { to } 0.28) \\
p=0.04\end{array}$ \\
\hline Leg length & 1026 & $0.053(1.00)$ & $-0.21(0.96)$ & $\begin{array}{l}0.21(0.07 \text { to } 0.35) \\
p=0.003\end{array}$ & $\begin{array}{l}0.24(0.11 \text { to } 0.37) \\
p<0.001\end{array}$ \\
\hline Body mass index & 1033 & $0.04 \quad(0.98)$ & $0.01(1.02)$ & $\begin{array}{l}-0.02(-0.17 \text { to } 0.12) \\
p=0.74\end{array}$ & $\begin{array}{l}-0.09(-0.23 \text { to } 0.05) \\
p=0.23\end{array}$ \\
\hline
\end{tabular}

Mean differences between breast fed and bottle fed subjects were calculated using random effects regression modelling.

* Internally age and sex standardised $z$ scores calculated for children aged 2 years to 14 years 9 months.

†Socioeconomic factors adjusted for were social class, number of children, birth order, and income category (all entered as categorical variables).

associated with greater childhood and adult stature in both males and females. Leg length was the component of childhood height that was most strongly related to breast feeding, perhaps reflecting the fact that leg length is the component of height most sensitive to prepubertal influences on growth. ${ }^{16}$

\section{Limitations}

If the socioeconomic covariates used to adjust for social and economic conditions in the 1930s were insufficiently detailed, or individuals were misclassified, then we may not have completely controlled for socioeconomic confounding (residual confounding). ${ }^{31}$ However, residual confounding is unlikely because the observed associations were not attenuated after controlling for a range of socioeconomic variables. We found no differences in mean parental height between breast fed and bottle fed infants in subsamples of the surveyed children. We also observed an association between breast feeding and childhood height when the analysis was restricted to within family height differences in relation to within family differences in breast feeding in an attempt to control for shared environmental and economic exposures influencing breast feeding and stature. There was no longer an association between breast feeding and later adult height in families with both breast and bottle fed infants $(n=70)$, although the wide confidence interval highlights the imprecision of this effect estimate. 


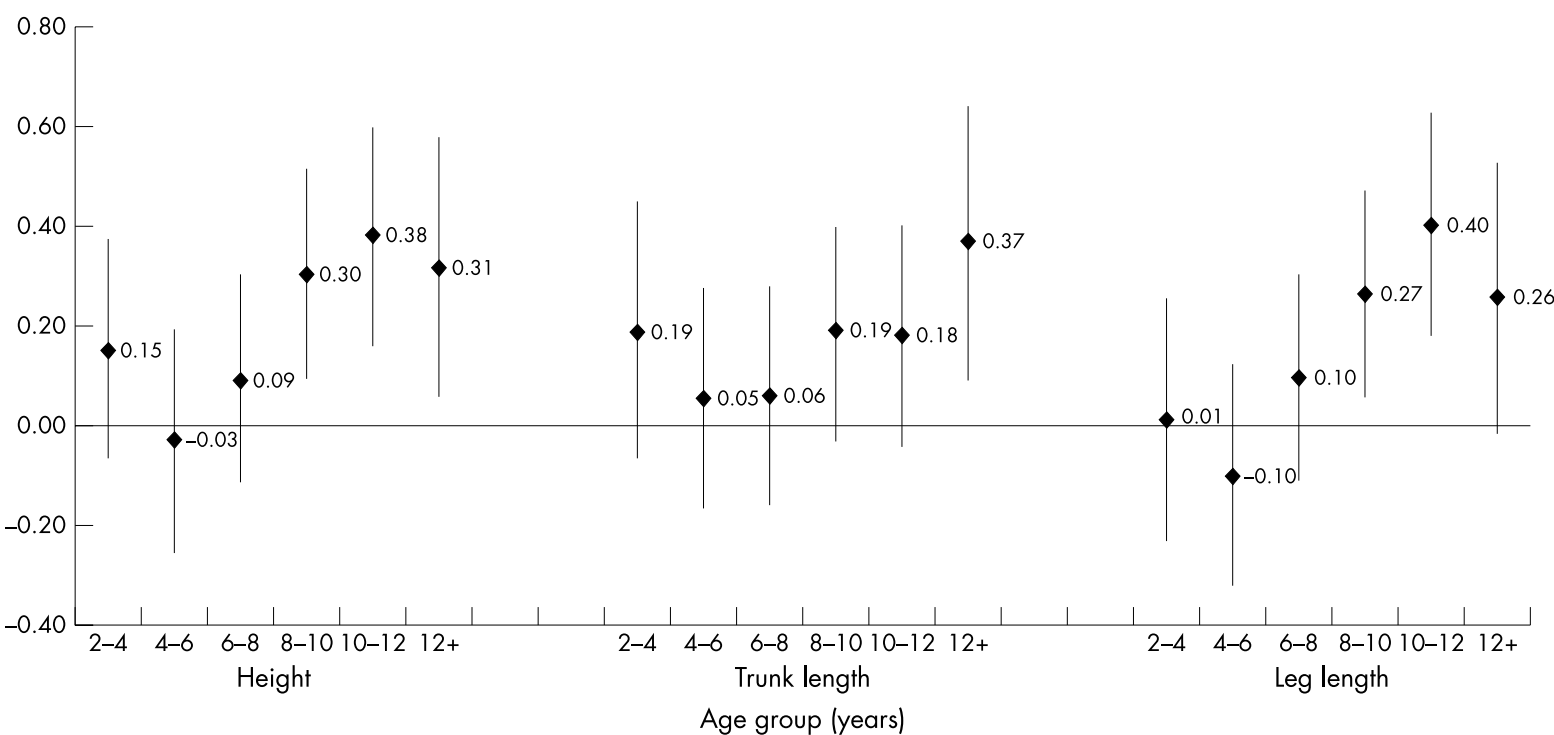

Figure 1 Age specific association in 2 year age bands between breast feeding and childhood height, Boyd-Orr cohort, UK. Mean differences between breast fed and bottle fed subjects calculated using random effects regression modelling and adjusted for clustering at the family level (sample sizes were too small for additional adjustments). Point estimates and $95 \%$ confidence intervals (Cl) are shown.

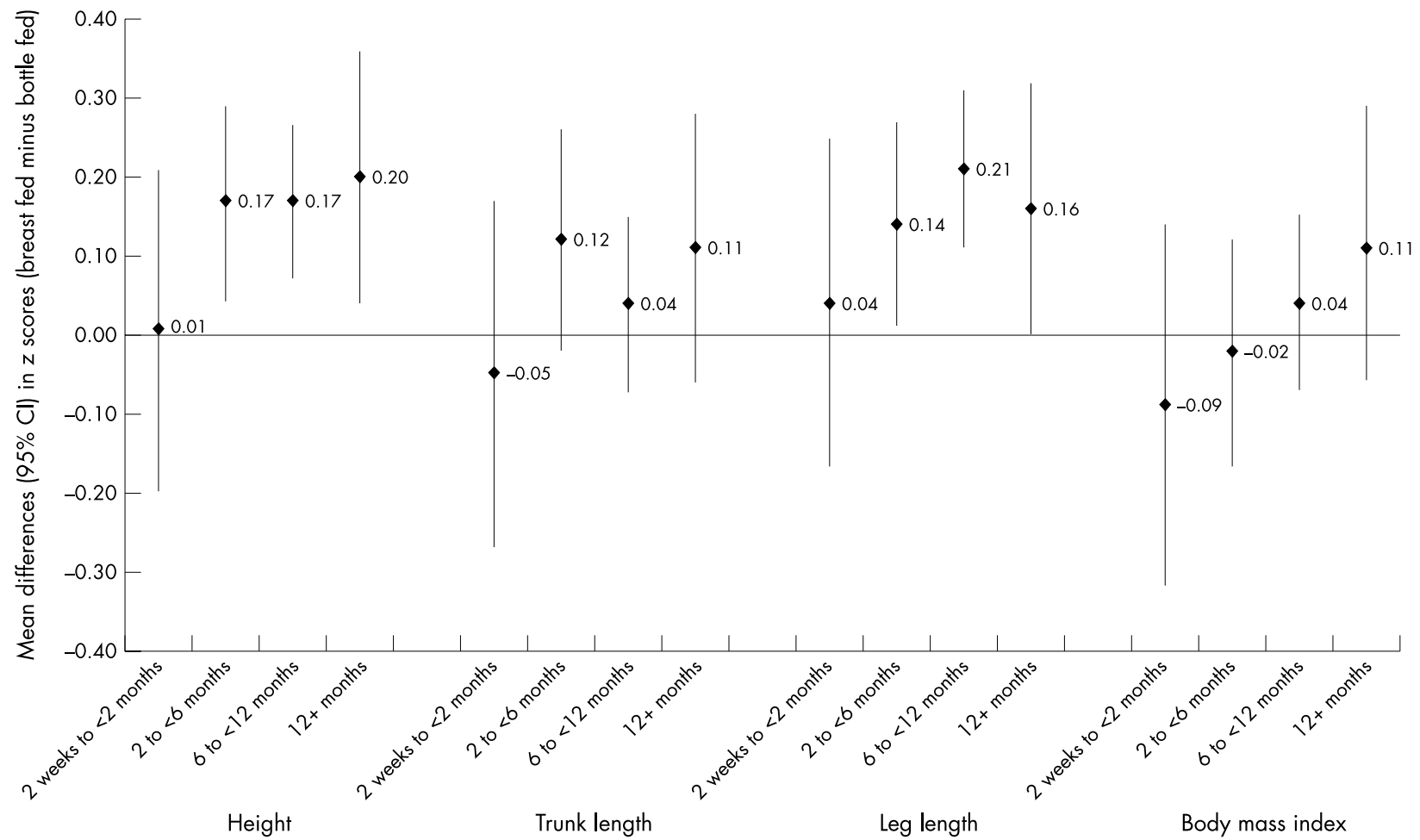

Figure 2 Association of breast feeding duration and childhood anthropometry, Boyd-Orr cohort, UK. Duration specific mean differences in anthropometric $z$ scores calculated using random effects regression modelling controlling for socioeconomic factors (social class, number of children, birth order, and income category all entered as categorical variables), clustering, and survey district. Point estimates and $95 \%$ confidence intervals $(\mathrm{Cl})$ are shown.

Adult heights were self reported, resulting in some misclassification. ${ }^{28}$ However, for this source of misclassification to explain the observed associations of breast feeding with adult height and leg length would require elderly adults who were breast fed as infants to over-report their height and leg length compared with elderly adults who were bottle fed. We believe that any misclassification bias is more likely to be non-differential, biasing the results towards the null value of no association rather than explaining the observed results.
It is also possible that sickly neonates were less likely to have been breast fed,,$^{10}$ and early poor health rather than breast feeding may have affected their growth. ${ }^{32}$ Furthermore, within-family differences in feeding patterns may reflect differences between family members in infant health. In observational studies, it is difficult to control for such effects; however, we found no differences in mean birth weights between breast fed and bottle fed infants in a subsample of the surveyed children. 
Table 5 Association between breast feeding and self reported adult stature, Boyd Orr cohort, UK

\begin{tabular}{|c|c|c|c|c|c|}
\hline \multirow[b]{2}{*}{ Variable } & \multirow[b]{2}{*}{$\begin{array}{l}\text { No in subset with } \\
\text { complete data }\end{array}$} & \multicolumn{2}{|l|}{ Mean (SD) } & \multicolumn{2}{|c|}{ Mean difference $(95 \% \mathrm{Cl})$ (breast fed minus bottle fed) } \\
\hline & & Breast fed & Bottle fed & $\begin{array}{l}\text { Adjusted for age* and } \\
\text { clustering at the family } \\
\text { level }\end{array}$ & $\begin{array}{l}\text { Also adjusted for } \\
\text { socioeconomic factorst } \\
\text { and survey district }\end{array}$ \\
\hline \multicolumn{6}{|l|}{ Males } \\
\hline Height $(\mathrm{cm})$ & 439 & $173.42(6.98)$ & $171.17(7.85)$ & $\begin{array}{l}2.38(0.81 \text { to } 3.94) \\
p=0.003\end{array}$ & $\begin{array}{l}2.49(0.94 \text { to } 4.03) \\
p=0.002\end{array}$ \\
\hline Trunk length $(\mathrm{cm})$ & 360 & $97.09(5.15)$ & $96.20(4.91)$ & $\begin{array}{l}0.91(-0.31 \text { to } 2.13) \\
p=0.15\end{array}$ & $\begin{array}{l}0.98(-0.27 \text { to } 2.14) \\
p=0.11\end{array}$ \\
\hline Leg length $(\mathrm{cm})$ & 368 & $76.31(4.97)$ & $75.47(4.63)$ & $\begin{array}{l}1.06(-0.10 \text { to } 2.23) \\
p=0.074\end{array}$ & $\begin{array}{l}1.25(0.09 \text { to } 2.40) \\
p=0.034\end{array}$ \\
\hline Body mass index & 431 & $27.20(5.24)$ & $26.62(5.19)$ & $\begin{array}{l}0.55(-0.55 \text { to } 1.65) \\
p=0.33\end{array}$ & $\begin{array}{l}0.60(-0.52 \text { to } 1.71) \\
p=0.29\end{array}$ \\
\hline \multicolumn{6}{|l|}{ Females } \\
\hline Height (cm) & 502 & $160.38(6.38)$ & $159.55(6.59)$ & $\begin{array}{l}0.95(-0.38 \text { to } 2.27) \\
p=0.16\end{array}$ & $\begin{array}{l}1.01(-0.27 \text { to } 2.29) \\
p=0.12\end{array}$ \\
\hline Trunk length $(\mathrm{cm})$ & 328 & $89.68(4.99)$ & $89.93(4.68)$ & $\begin{array}{l}-0.38(-1.65 \text { to } 0.89) \\
p=0.56\end{array}$ & $\begin{array}{l}-0.64(-1.91 \text { to } 0.62) \\
p=0.32\end{array}$ \\
\hline Leg length $(\mathrm{cm})$ & 335 & $70.81(4.95)$ & $69.85(5.41)$ & $\begin{array}{l}1.24(-0.04 \text { to } 2.51) \\
p=0.057\end{array}$ & $\begin{array}{l}1.17(-0.08 \text { to } 2.42) \\
p=0.067\end{array}$ \\
\hline Body mass index & 483 & $27.71(6.83)$ & $28.00(7.61)$ & $\begin{array}{l}-0.08(-1.51 \text { to } 1.36) \\
p=0.92\end{array}$ & $\begin{array}{l}-0.28(-1.70 \text { to } 1.15) \\
p=0.70\end{array}$ \\
\hline
\end{tabular}

Mean differences (natural units) were calculated using random effects regression modelling.

*Age entered in these models as a categorical variable (quintiles).

†Socioeconomic factors adjusted for were social class, number of children, birth order, and income category (all entered as categorical variables).

Biased recall of breast feeding is unlikely to explain our results because the recall period was relatively short in our study and several reports show close agreement between long term recall and postnatal records. ${ }^{33}$

\section{Comparison with other studies}

The constitution of artificial feeds has changed over the course of the last century. In the past, infants who were artificially fed were given fresh cows milk with added sugar, patent preparations of dried cows milk, machine skimmed condensed milk, or patent foods made from wheatflour or arrowroot. ${ }^{1025}$ It is difficult to assess whether such differences would be observed between infants breast fed and formula fed today. The quality of alternatives to breast feeding in the 1920s and 1930s may underlie the positive associations observed between breast feeding and linear growth, raising uncertainty about the contemporary relevance of our results. The observed associations are, however, suggestive of an important role of infant feeding on later growth, which may be of particular relevance in developing countries where large numbers of people do not have access to modern infant formula milk, clean water, sewage disposal, or fuel..$^{34}$ In developed countries, the association between breast feeding and linear growth suggests that infant nutrition may be a biologically relevant exposure underlying the height and leg length mortality associations observed in cohorts born in the 1920s and 1930s..$^{13637}$

In agreement with several previous studies, we found no association between breast feeding and childhood BMI, ${ }^{3}$ although a more recent study showed a protective association of breast feeding on overweight and obesity. ${ }^{20}$ The differences between the recent study and our results may be explained by differences in the alternatives to breast feeding between 1920 and 1990, or incomplete adjustment for social and economic differences in breast feeding, ${ }^{22}$ which are more pronounced now than in the 1920s and 1930s. ${ }^{25}$ The absence of an association between breast feeding and BMI in subjects at age 60-80 years does not exclude the possibility of an association at younger ages.

Reports on the influence of breast feeding on childhood height in more recent birth cohorts provide conflicting results. Some show no association between breast feeding and height up to 7 years of age, but unlike this paper there are no studies in later childhood or adulthood. ${ }^{38}{ }^{39}$ Another study found that breast fed children were significantly taller than formula fed children at age 7 years, but that the association disappeared in a multivariable model. However, this model included skeletal maturity as a covariate, which may have had the effect of over-controlling for a factor on the causal pathway-for example, if breast feeding influences maturity. ${ }^{40}$

The breast feeding rates observed in this cohort were relatively high (ever: $72.7 \%$; over six months: $41.9 \%$ ) compared with more recent breast feeding patterns (ever: $66 \%$; over six months: $22 \%) .{ }^{21}$ However, our breast feeding rates mirror those derived from contemporaneously published literature ${ }^{41}$ In line with findings from studies conducted in the 1930 s and 1940s, we found a relatively weak relation between markers of economic status and a history of ever having been breast fed. ${ }^{42}$

\section{Mechanisms}

There are a number of possible reasons for the association between breast feeding and later height. These include $(a)$ setting of the growth trajectory through optimum nutrition ${ }^{32}$; (b) protection against enteric or respiratory infections which were more common in those who were artificially fed ${ }^{1025}$; (c) the potential psychological effects of breast feeding and maternal bonding on future upbringing ${ }^{43} ;(d)$ the establishment of taste thresholds and behavioural patterns of eating that influence later growth. ${ }^{25}$ It is not possible within this dataset to assess which of these is more likely. We found no evidence of interaction between breast feeding and family income on height, suggesting that the impact of infant feeding method is not greater among those who are poorer (who would be expected to be exposed to adverse conditions, predisposing for example to respiratory and enteric infections).

The reasons why the association of breast feeding with height was more pronounced after mid-childhood are unclear. If breast feeding increased stature by improved nutrition alone, we would have expected breast feeding associations with height to be more pronounced in younger children. There are a number of possible explanations for this finding. Firstly, it may have been a chance result. Secondly, as the surveyed children included in the analysis were aged $2-14$ years, the age 
interaction could reflect changes in the alternatives to breast feeding among different birth cohorts. However, the switch to formula type milk consisting of full cream powders did not begin until the 1940s, after the survey was completed..$^{25}$ Finally, it has been suggested that physiological or metabolic "programming" occurs at critical periods in early development and determines events in later life. ${ }^{44}$

Breast feeding influences neonatal levels of various hormones affecting growth, ${ }^{45}{ }^{46}$ including insulin-like growth factors. ${ }^{47}$ Evidence for a "programming" effect of breast feeding comes from studies suggesting that early nutrition influences expression of growth hormone receptor on the growth plates of long bones in late infancy, ${ }^{48}$ and that the timing of menarche is related to environmental factors operating near birth. ${ }^{49}$ The pattern of human linear growth can be divided into three phases, each with a specific hormone profile: infancy, childhood, and puberty. ${ }^{50}$ The possible mechanisms underlying our observation of an association between breast feeding and height above 8 years of age are speculative, but may have plausibly arisen in either of two ways. Firstly, breast feeding may influence growth tempo-that is, the rate at which a child matures-throughout childhood such that breast fed children are more advanced into puberty and hence taller. $^{51}$ The suggestion of a linear increase in the effect of breast feeding on height and leg length throughout childhood (fig 2) lends support to this possibility. Secondly, breast feeding may differentially influence growth at puberty compared with earlier life. If growth tempo were the whole explanation, differences in height between breast fed and bottle fed children would disappear after puberty and adult heights would be similar. However, we also found an association between breast feeding and adult height, suggesting an effect of breast feeding on height over and above the rate at which a child matures.

\section{Conclusions}

We have shown that stature was related to breast feeding in children surveyed in the 1930s and that this association persisted into adulthood. We found no evidence that breast feeding in the 1920s and 1930s influenced childhood or adult BMI. Longer term studies have shown that breast feeding is associated with adult mortality and morbidity, but the mechanisms linking breast feeding to later health are unclear. ${ }^{1}$ One potential mechanism may lie on the same pathway as that linking height to future mortality. ${ }^{13}$

\section{ACKNOWLEDGEMENTS}

We thank the following: Professor Philip James, director of The Rowett Research Institute, for the use of the archive, and in particular Walter Duncan, honorary archivist to the Rowett; the staff at the NHS Central Register at Southport and Edinburgh; Sara Bright for data entry; Jonathan Sterne for statistical advice; Mark Taylor for entering breast feeding data; and Professor John Pemberton for information on the conduct of the original survey. We also acknowledge all the research workers who participated in the original survey in 1937-1939. RMM is supported by the Wellcome Trust.

\section{Authors' affiliations}

R M Martin, G Davey Smith, S Frankel, D Gunnell, Department of Social Medicine, University of Bristol, Canynge Hall, Whiteladies Road, Bristol BS8 2PR, UK

P Mangtani, Department of Epidemiology and Population Health, London School of Hygiene and Tropical Medicine, Keppel Street, London WCIE 7HT, UK

\section{REFERENCES}

1 Golding J, Emmett PM, Rogers IS. Does breast-feeding have any impact on non-infectious, non-allergic disorders? Early Hum Dev 1997;49:S131-42

2 Marmot MG, Page CM, Atkins $E$, et al. Effect of breast feeding on plasma cholesterol and weight in young adults. J Epidemiol Community Health 1980;34:164-71.
3 Ravelli ACJ, van der Meulen, Osmond C, et al. Infant feeding and adult glucose tolerance, lipid profile, blood pressure, and obesity. Arch Dis Child 2000;82:248-52

4 Fall CHD, Barker DJP, Osmond C, et al. Relation of infant feeding to adult serum cholesterol concentration and death from ischaemic heart disease. BM 1992:304:801-5.

5 Pettitt DJ, Forman MR, Hanson RL, et al. Breastfeeding and incidence of non-insulin-dependent diabetes mellitus in Pima Indians. Lancet 1997;350:166-8

6 Fall CHD, Goggin PM, Hawtin P, et al. Growth in infancy, infant feeding, childhood living conditions, and Helicobacter pylori infection at age 70. Arch Dis Child 1997:77:310-14.

7 Wingard DL, Criqui $\mathrm{MH}$, Edelstein SL, et al. Is breast-feeding associated with adult longevity? Am J Public Health 1994;84:1458-62.

8 Mott GE, Jackson EM, DeLallo L, et al. Differences in cholesterol metabolism in juvenile baboons are programmed by breast- versus formula-feeding. J Lipid Res 1995;36:299-307.

9 Glicksman MD, Kawachi I, Hunter D, et al. Childhood socioeconomic status and risk of cardiovascular disease in middle aged US women: a prospective study. J Epidemiol Community Health 1995;49:10-15.

10 Fildes V. Breast-feeding in London, 1905-19. J Biosoc Sci 1992;24:53-70.

11 Douglas JWB. The extent of breast feeding in Great Britain in 1946, with special reference to the health and survival of children. J Obstet Gynaecol Br Empire 1950;57:335-61.

12 Tanner JM. Growth as a mirror of the conditions of society: secular trends and class distinctions. In Demirjan A, Brault Dubuc M, eds. Human growth: a multidisciplinary review. London: Taylor \& Francis, 1986.

13 Gunnell DJ, Davey Smith G, Frankel S, et al. Childhood leg length and adult mortality: follow-up study of the Carnegie (Boyd Orr) survey of diet and health in pre-war Britain. J Epidemiol Community Health 1998; 52:142-52.

14 Hart CL, Hole DJ, Smith GD. Risk factors and 20-year stroke mortality in men and women in the Renfrew/Paisley study in Scotland. Stroke 1999;30: 1999-2007

15 Strandberg TE. Inverse relation between height and cardiovascular mortality in men during 30-year follow-up. Am J Cardiol 1997:80:349-50.

16 Gunnell DJ, Davey Smith G, Frankel SJ, et al. Socio-economic and dietary influences on leg length and trunk length in childhood: a reanalysis of the Carnegie (Boyd Orr) survey of diet and health in prewar Britain (1937-39). Paediatr Perinat Epidemiol 1998;12 (suppl 1):96-113.

17 Billewicz WZ, Thomson AM, Fellowes HM. A longitudinal study of growth in Newcastle upon Tyne adolescents. Ann Hum Biol 1983;10:125-33

18 Wadsworth MEJ, Hardy RJ, Paul AA, et al. Leg and trunk length at 43 years in relation to childhood health, diet and family circumstances; evidence from the 1946 national birth cohort. Int J Epidemiol 2002;31:383-90.

19 Gunnell, D. Can adult anthropometry be used as a biomarker for prenatal and childhood exposures? Int J Epidemiol 2002;31:390-4.

20 Von Kries R, Koletzko B, Sauerwald T, et al. Breast feeding and obesity: cross sectional study. BM 1999:319:147-50.

21 Foster K, Lader, Cheesborough S. Infant feeding 1995: a survey of infant feeding practices in the United Kingdom carried out by the Social Survey Division of ONS on behalf of the Department of Health, the Scottish Office Department of Health, the Welsh Office and the Department of Health and Social Services in Northern Ireland. London: The Stationery Office, 1997

22 Wadsworth M, Marshall S, Hardy R, et al. Breast feeding and obesity: relation may be accounted for by social factors. BM 1999;319:1576

23 Rowett Research Institute. Family diet and health in pre-war Britain. Dunfermline: Carnegie United Kingdom Trust, 1955.

24 Gunnell DJ, Frankel S, Nanchahal K, et al. Lifecourse exposure and later disease: a follow-up study based on a survey of family diet and health in pre-war Britain (1937-1939). Public Health 1996;1 10:85-94.

25 MRC. Infant nutrition and cardiovascular disease. Scientific Report No 8 Southampton: MRC Environmental Epidemiology Unit, 1987.

26 Gunnell DJ, Frankel S, Nanchahal K, et al. Childhood obesity and adult cardiovascular mortality: a 57-y follow-up study based on the Boyd-Orr cohort. Am J Clin Nutr 1998;67:1111-18.

27 Kemp M, Gunnell D, Davey Smith G, et al. Finding and using inter-war maternity records. Social History of Medicine 1997;10:305-29.

28 Gunnell DJ, Berney L, Holland P, et al. How accurately are height, weight and leg length reported by the elderly and how closely are they related to measurements recorded in childhood? Int J Epidemio 2000;29:456-64.

29 StataCorp. Stats statistical software: release 7.0. College Station, TX: Stata Corporation, 2001.

30 Anonymous. Cluster. Stata reference manual release 7 volume 1A-G. College Station, TX: Stata Press, 2001:224-35.

31 Davey Smith G, Phillips AN. Confounding in epidemiological studies: why "independent" effects may not be all they seem. BM 1992;305:757-9.

32 Rogers IS, Emmett PM, Golding J. The growth and nutritional status of breast-fed infants. Early Hum Dev 1997:49:S157-74.

33 Kark JD, Troya G, Friedlander Y, et al. Validity of maternal reporting history and the association with blood lipids in 17 year olds in Jerusalem. J Epidemiol Community Health 1984;38:218-25.

34 Cunningham AS. Breastfeeding: adaptive behavior for child health and longevity. In: Macadam PS, Dettwyler KA, eds. Breastfeeding: biocultural perspectives. New York: Aldine de Gruyter, 1995:243-64. 
35 WHO Collaborative Study Team on the Role of Breastfeeding in the Prevention of Infant Mortality. Effect of breastfeeding on infant and child mortality due to infectious diseases in less developed countries: a pooled analysis. Lancet 2000;355:451-5.

36 Gunnell DJ, Davey Smith G, Holly JMP, et al. Leg length and risk of cancer in the Boyd Orr cohort. BM 1998;317:1350-1.

37 Davey SG, Greenwood R, Gunnell D, et al. Leg length, insulin resistance, and coronary heart disease risk: the Caerphilly study. J Epidemiol Community Health 2001;55:867-72.

38 Baranowski T, Bryan GT, Harrison JA, et al. Height, infant-feeding practices and cardiovascular functioning among 3 or 4 year old children in three ethnic groups. J Clin Epidemiol 1992;45:513-18.

39 Wilson AC, Forsyth JS, Greene SA, et al. Relation of infant diet to childhood health: seven year follow up of cohort of children in Dundee infant feeding study. BMU 1998:316:21-5.

40 Birkbeck JA, Buckfield PM, Silva PA. Lack of long-term effect of the method of infant feeding on growth. Human Nutrition: Clinical Nutrition 1985;39C:39-44

41 Ross Al. Breast-feeding in Bristol. Lancet 1951;i:630-2.

42 Robinson M. A comparison of breast-feeding in ten classes of the population. Arch Dis Child 1941;16:31-4.
43 Peck MN, Lundberg $O$. Short stature as an effect of economic and social conditions in childhood. Soc Sci Med 1995;41:733-8.

44 Lucas A, Fewtrell MS, Cole TJ. Fetal origins of adult disease: hypothesis revisited. BM 1999:319:245-9.

45 Lucas A, Sarson DL, Blackburn AM, et al. Breast vs. bottle: endocrine responses are different with formula feeding. Lancet 1980;1:1267-9.

46 Phillips DI, Barker DJ, Osmond C. Infant feeding, fetal growth and adult thyroid function. Acta Endocrinol 1993;129:134-8.

47 Diaz-Gomez NM, Domenech E, Barroso F. Breast-feeding and growth factors in pre-term newborn infants. J Pediatr Gastroenterol Nutr 1997:24:322-7.

48 Waterlow JC. Summary of causes and mechanisms of linear growth retardation. Eur J Clin Nutr 1994;48(suppl 1):S210.

49 Liestol K. Social conditions and menarcheal age: importance of early years of life. Ann Hum Biol 1982;22:199-205.

50 Karlberg J. A biologically orientated mathematical model (ICP) for human growth. Acta Paediatr Scand 1989; suppl 350:70-94

51 Graffar $M$, Corbier J. Contribution to the study of the influence of socio-economic conditions on the growth and development of the child. Early Child Development and Care 1972;1:141-79.

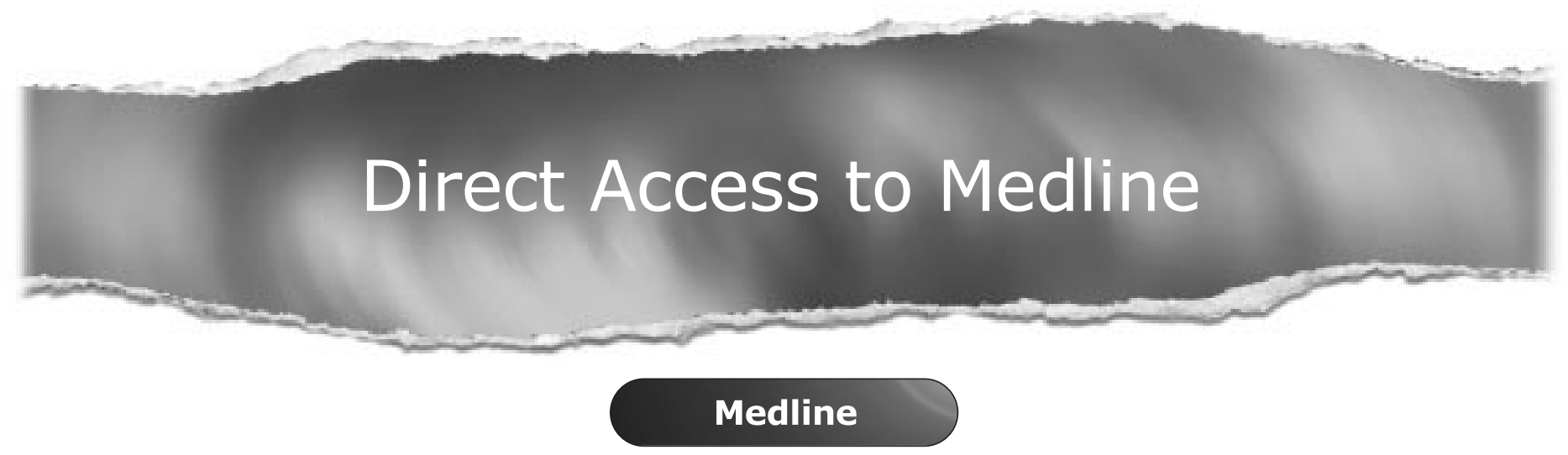

Link to Medline from the homepage and get straight into the National Library of Medicine's premier bibliographic database. Medline allows you to search across 9 million records of bibliographic citations and author abstracts from approximately 3,900 current biomedical journals.

www.archdischild.com 